\title{
O MOVIMENTO DA PRODUÇÃO ACADÊMICA SOBRE A REDE MUNICIPAL DE EDUCAÇÃO DE BELO HORIZONTE
}

\author{
Samira Zaidan* \\ Anna Maria Salgueiro Caldeira** \\ Eustáquia Salvadora de Sousa*** \\ Ana Lúcia de Faria Azevedo**** \\ Cláudia Caldeira Soares****
}

RESUMO: Este artigo apresenta uma análise da produção acadêmica sobre a Rede Municipal de Educação de Belo Horizonte, de 1986/2005, considerando o contexto histórico social e educacional referente ao período. As 162 dissertações e teses que integram o estudo foram organizadas em 12 "focos temáticos". Os trabalhos desenvolvidos ao longo desses vinte anos revelam uma riqueza de temas e problemas e expressam um deslocamento do "olhar" dos pesquisadores das questões mais gerais para as mais específicas, em que a escola e seus sujeitos são colocados no centro do sistema educacional. São analisadas práticas escolares, programas da escola e de governo, projetos e os docentes e discentes em seus saberes, memórias, histórias de vida, relativas aos níveis de ensino da educação básica. A instituição escolar é entendida como um tempo/espaço de formação de sujeitos e de vivência de conflitos e possibilidades. O estudo revela uma rede de escolas que chama a atenção pelo número de trabalhos nela referenciados, pela diversificação de teorias e temas abordados, pela contribuição que deixa para a elaboração de projetos e políticas públicas.

Palavras-chave: Estado do Conhecimento; Rede Municipal de Belo Horizonte; Escola Plural

\footnotetext{
* Doutora em Educação. Participante do PRODOC/FaE/UFMG - Grupo de Pesquisa sobre Condição e Formação Docente e Professora da Universidade Federal de Minas Gerais (UFMG).E-mail:samira@fae.ufmg.br

** Doutora em Educação. Participante do PRODOC/FaE/UFMG - Grupo de Pesquisa sobre Condição e Formação Docente e Professora da Pontificia Universidade Católica de Minas Gerais (PUC Minas).E-mail: annacald@terra.com.br

*** Doutora em Educação. Participante do PRODOC/FaE/UFMG - Grupo de Pesquisa sobre Condição e Formação Docente e Professora da Pontíficia Universidade Católica de Minas Gerais (PUC Minas).E-mail:eustaquiasousa@terra.com.br

**** Mestre em Educação. Participante do PRODOC/FaE/UFMG - Grupo de Pesquisa sobre Condição e Formação Docente e Professora da Rede Municipal de Ensino de Belo Horizone (RMEBH).E-mail:ana03faria@ig.com.br

**** Mestre em Educação. Participante do PRODOC/FaE/UFMG - Grupo de Pesquisa sobre Condição e Formação Docente e Professora da Rede Municipal de Ensino de Belo Horizone (RMEBH) e Universidade Presidente Antônio Carlos (UNIPAC).E-mail: claudia_caldeira@uol.com.br
} 


\section{THE MOVEMENT OF THE PRODUCTION ABOUT THE MUNICIPAL ACADEMIC PRODUCTION}

ABSTRACT: The present article analyzes the academic production on/in the Municipal Educational System of Belo Horizonte - from 1986 to 2005 -, considering the social, educational and historical contexts of this period. The 162 dissertations and theses that integrate this study have been organized in 12 themes, all analyzed by specialist researchers. The development of the investigations, throughout the twenty years considered, shows a great variety of subjects and problems, and expresses a displacement of the researchers' look, from a general to a particular approach, in which the schools, educational professionals and students, as well as their actions, are placed in the center of the educational system. This research analyzes school practices, school and government programs, projects, teachers' and students' practices, their knowledge, memories and life stories, all related to the different levels of basic education. School is understood as a time/space entity where people get education, face conflicts and find possibilities. The Municipal Educational System of Belo Horizonte stands out for the number of researches focused on itself, the diversification of approached themes and theories, and the contribution it may bring to new projects and public politics.

Keywords: State of knowledge; Municipal Educational System of Belo Horizonte ; Escola Plural (Plural School)

\section{INTRODUCุÃO}

A análise apresentada neste artigo foi construída com base em uma leitura diacrônica dos resultados da pesquisa "Estado do conhecimento sobre/na Rede Municipal de Educação de Belo Horizonte 1986-2005", em que foram consideradas dissertações e teses produzidas no período de vinte anos ${ }^{2}$.

$\mathrm{O}$ estudo desse conjunto de dissertações e teses visa a ampliar os conhecimentos sobre a Rede Municipal de Educação de BH (RME-BH), apontar avanços e desafios que possam subsidiar a prática docente, as políticas públicas e o debate acadêmico sobre as pesquisas em Educação no Brasil.

O período considerado pela pesquisa - 1986/2005 - justifica-se por uma combinação de fatores: trata-se de um período histórico de mudanças políticas globais e, no país, de um processo de democratização. Nessa fase, intensificaram-se os movimentos sociais, entre eles, o movimento educacional docente. Especificamente na RME-BH, nesses anos, destacaram-se mobilizações de grupos de professores e iniciativas de governos por mudanças na escola, no sentido da universalização da educação e da constituição do sistema municipal de educação. Foi significativa a produção acadêmica desenvolvida a partir do I Congresso Mineiro de Educação (1984) e outros congressos e conferências de âmbito municipal que se seguiram, eventos esses considerados marcos 
históricos na tomada de decisões e na formulação de propostas políticas e pedagógicas.

As 162 dissertações e teses analisadas abordam diferentes aspectos relativos à organização e ao funcionamento da educação no município e aos sujeitos sociais envolvidos. O registro desse acervo foi organizado em fichas de identificação de cada obra, acompanhada da reprodução dos respectivos resumos. O Quadro I, ao final, apresenta a distribuição da produção.

Optou-se por uma classificação dos trabalhos em "focos temáticos", agrupamento que possibilitou reunir a maioria das pesquisas que se aproximavam pelo objeto focalizado, ainda que apresentassem temas, objetivos e abordagens teórico-metodológicas diferentes e diversificadas. Foram doze os focos temáticos considerados: Alfabetização e Letramento; Avaliação; Diversidade e Inclusão; Educação de Jovens e Adultos; Educação e Tecnologias; Formação Docente; Infância e Educação Infantil; Juventude e Escola; Políticas Públicas e Gestão; Prática Pedagógica; Relação Família e Escola; Trabalho Docente. O Quadro II, ao final deste texto, apresenta a distribuição do acervo por foco temático.

A produção, ainda incipiente no início do período pesquisado, apresenta crescimento gradativo no final dos anos 1990 e nos anos 2000. Esse crescimento pode estar relacionado a dois fatores principais: a implantação do Programa Escola Plural, desde 1995, que colocou esta rede de escolas em destaque no quadro das reformas educacionais do país, e o aumento das vagas na pós-graduação da Faculdade de Educação/ UFMG. No universo pesquisado, muitos são os pesquisadoresprofessores das escolas municipais, usufruindo do direito à licença profissional remunerada para formação. Como veremos a seguir, a RME$\mathrm{BH}$ viveu, nesse período, intenso debate pedagógico, o que instigou os docentes a buscarem elementos para melhor compreender os movimentos de reforma e mudança que se desenvolviam nas escolas.

Este artigo considerou todas as pesquisas do período, mas destinou um "olhar" mais acurado às teses e às dissertações que enfocaram questões "sobre" a RME-BH, tais como aquelas que analisam políticas e caracterizam perfis.

A análise dos trabalhos, agrupados por "focos temáticos", coube a pesquisadores especialistas em cada área contemplada. Ao final, a equipe responsável pela pesquisa construiu uma análise temporal da produção, situando ao longo dos vinte anos considerados as dissertações e teses apresentadas nesse artigo. 


\section{A PRODUÇÃO ACADÊMICA SOBRE/NA RME-BH}

A produção tem início nos anos 1980. Nessa década, foram localizados dois trabalhos: as dissertações de Oliveira (1986) e de Prado $(1987)^{2}$. Ambos os estudos destacam o fenômeno do fracasso escolar: "evasão e repetência se reproduzem em massa na primeira série, e são os filhos de classes trabalhadoras que mais são atingidos..." (OLIVEIRA, 1986, p. 19). Os trabalhos consideram que o fracasso escolar não pode mais ser atribuído às supostas deficiências culturais dos alunos pobres e, sim, às diferenças econômicas e culturais na relação dessa população com a escola. Situam a existência de um conflito cultural na escola, devido à imposição de códigos e conhecimentos por parte da "elite" a todos os estudantes, de todos os grupos sociais. Diante disso, perguntam os pesquisadores: o que está acontecendo na sala de aula e no cotidiano da escola?

Nesses primeiros trabalhos, os pesquisadores assumem uma posição de denúncia da situação. Buscam, nas teorias de Bourdieu e Passeron $(1970)^{3}$, elementos para compreender e analisar os mecanismos que, no interior da escola, "transformam as desigualdades sociais em desigualdades escolares", e desmistificam a "ideologia do dom". A escola é considerada uma instituição reprodutora da cultura dominante que contribui para a manutenção dos privilégios de classe e que, ao se tornar acessível às classes populares, produz um choque de culturas.

Esses dois trabalhos destacam-se não só por lançar novas idéias sobre a situação do fracasso escolar, mas também por antecipar um leque de novas questões que estarão presentes e se desdobrarão em trabalhos futuros.

Do ponto de vista metodológico, as abordagens dessas duas dissertações são definidas como estudo de caso de tipo etnográfico. Esse enfoque exige uma imersão no mundo dos educandos, buscando compreender e valorizar suas linguagens, seus valores e seus comportamentos e confrontá-los com as linguagens, os valores e os comportamentos da escola.

É importante destacar ainda que as abordagens de Oliveira (1986) e Prado (1987) relativas à escolarização de estudantes das camadas populares ao mesmo tempo que buscam compreender e analisar a realidade escolar, fazem contundente defesa de uma nova proposta de escola, que inclua os até então excluídos. Salientam, também, a presença de conhecimentos próprios dessas camadas sociais no cotidiano escolar.

Desse modo, embora o número de trabalhos dos anos 1980 seja restrito, eles expressam muito bem o debate emergente na educação para aquele momento. 
Trata-se de um período extremamente rico para a retomada das questões referentes à relação educação e sociedade, no contexto de esgotamento do regime ditatorial. Foram anos de vivência de mudanças, de luta para a eleição direta do presidente da república, de ampliação dos movimentos sociais e dos partidos políticos, num contexto de debate e intensa reorganização política em vários níveis da sociedade civil. Também nesse período foi reescrita a Constituição Federal, mobilizando e confrontando diferentes grupos e interesses sociais, entre eles os relativos à educação.

Nesse contexto, foi constituído um fórum que propôs uma pauta nacional para a educação, referenciada nas bandeiras de lutas dos grupos sociais, propondo novas formulações para a Constituição, tais como: a defesa do ensino público e gratuito em todos os níveis; a democratização do acesso; a permanência e a gestão educacional; e a abertura ao pluralismo social (PINHEIRO, 1996). Em 1988, foi votada uma nova Constituição Federal permeada por essas idéias.

Nessa perspectiva, Neidson Rodrigues (2000, p. 123-125) considera esses anos "um período que foi uma passagem e uma construção": de um lado, o regime ditatorial, que, apoiado na "doutrina da segurança nacional", impunha um modelo educacional para "assegurar a racionalidade técnica ao desenvolvimento econômico e ao papel regencial do estado autoritário"; de outro lado, as mobilizações sociais, especificamente de docentes, vêm colocar em foco os direitos sociais e o respeito à diversidade. Segundo o autor, alarga-se "a consciência pública da necessidade de expansão e melhoria da qualidade da educação escolar” (p. 126), independentemente dos aportes teóricos e ideológicos presentes nas diversas proposições e análises políticas do período, o que vai levar a uma discussão mais intensa sobre "a natureza e a função da educação escolar". E, ainda, segundo o autor, estavam na ordem do dia, nos anos 1980, questões como: a democracia nas relações internas e na gestão escolar; eleições para diretor; constituição de colegiados escolares; concurso para admissão nas escolas; e criação de comissões municipais de educação. Soma-se a tudo isso o "mote" educação para todos, que ganhou dimensão política no estado e no Brasil. É o que se evidencia nos trabalhos acadêmicos sobre/na RME-BH na década seguinte.

É importante recordar, também, que, nesse período (1983), foi realizado I Congresso Mineiro de Educação, com a participação de 1200 delegados de todo o estado. Foi elaborado o documento ("Diretrizes para a Educação Mineira"), com idéias-chave tais como a criação de colegiados escolares, a eleição para diretores, a realização de concursos para admissão 
de professores, a ampliação do tempo para a alfabetização, colocadas na ordem do dia da educação.

Outro momento de destaque desse período foi a realização do I Congresso Político-Pedagógico da RME-BH, em 1989, com a participação da comunidade escolar, no qual foram deliberadas questões relativas às funções da escola, à sua organização e às normas e critérios para o seu "quadro" de pessoal. Nesse sentido, Rocha (2006) destaca que "grande parte das resoluções do I Congresso foram incorporadas no capítulo referente à educação na Lei Orgânica do Município, votada no final de 1990". Como exemplo, é colocada a necessidade de cada escola elaborar o seu projeto político-pedagógico. Entre as inúmeras questões de importância para a educação municipal, tratadas no I Congresso, destacase a criação do Centro de Aperfeiçoamento do Profissional da Educação (CAPE), uma verdadeira escola de formação profissional em serviço. Esse Centro vem a se constituir como espaço de discussão e formação, participando ativamente da política educacional. Será, também, tema de futuros trabalhos acadêmicos.

Nesse período, nas escolas municipais de Belo Horizonte, são desenvolvidos, por grupos de docentes, os "projetos pedagógicos", que, segundo Rocha (2006), representaram as "primeiras tentativas de renovação nas escolas". Os projetos pedagógicos eram diversificados e contemplavam múltiplas questões do cotidiano escolar, tais como: a ampliação do tempo do aluno na escola, com atividades culturais e esportivas; aulas de recuperação; avaliações contínuas; incorporação de crianças com menos de sete anos no ano inicial do ensino fundamental; educação de jovens e adultos; entre outras inovações. Os projetos, de autoria dos próprios docentes, se baseavam nas condições e demandas da escola e eram construídos a partir de uma reflexão coletiva sobre a educação naquele momento, propondo e desenvolvendo diversas ações transformadoras. Grupos de professores multiplicaram-se e professoras alfabetizadoras da RME-BH organizaram seminários e congressos. Ao longo do período estudado, muitos são os trabalhos que analisam os processos de democratização nas escolas municipais, especialmente os relatos de práticas e projetos.

Rocha (2006) lembra ainda que são fortes as reivindicações para a democratização da gestão escolar, levando algumas escolas a realizar eleição direta para diretores, à revelia da legislação vigente. Esse fato provocou enfrentamentos e contribuiu para a ampliação e o fortalecimento das relações democráticas na escola e para a institucionalização 
da eleição livre e direta para diretores. Notadamente, destaca-se, nos debates, o tema central sobre a democratização das estruturas da escola, e a realização de eleições para diretores vai reordenar os sistemas decisórios, rompendo com a lógica das indicações e dos interesses políticos eleitorais, apresentando novas questões para a gestão. Uma delas, que merece destaque, é o novo "lugar" ocupado pelos docentes na escola, para além da docência: nas coordenações pedagógicas e nas direções das escolas.

Isso tudo mostra que os anos 1980, para as escolas municipais de Belo Horizonte, podem ser caracterizados como anos de articulação, de congregação de grupos, de elaboração de projetos que analisam e discutem a escola pública. Assim, o movimento pedagógico vivido pela RMBH acompanha a situação nacional do país, com a ampliação dos movimentos sociais e a democratização das estruturas e instituições. Muitos desses temas serão enfocados nas dissertações e teses da década de 1990, mostrando como professores e pesquisadores se preocupavam em compreender melhor o contexto e avançar nas elaborações teóricas a partir da análise dele.

Também a universidade desempenha importante papel nos anos 1980, tanto por meio do movimento estudantil, quanto do movimento docente. Neidson Rodrigues (2000, p. 129) destaca, como forte característica desse período, a formação dos "identificados como intelectuais orgânicos no interior dos próprios movimentos sociais (...) formados nos Centros Universitários comprometidos com a produção e o desenvolvimento de um movimento de difusão da consciência crítica na sociedade brasileira". Como exemplo, o autor destaca a organização de cursos de pós-graduação na PUC de São Paulo e na UFMG, entre outros.

No mesmo período, Miguel Arroyo observa que o Programa de Mestrado da FAE- UFMG, onde se desenvolveu a maior parte dos trabalhos aqui analisados, busca romper com a perspectiva de aperfeiçoamento orientada pelos "critérios de rendimento, produtividade e eficiência", presente nos anos 1970. Desenvolve-se, assim, uma reforma curricular que privilegia o "ensino como um processo de interação social", em que "a relação educação-sociedade" é o tema central das disciplinas oferecidas. Os estudos focavam o quê e "para quem" ensinar (1982, p. 108). Segundo o autor, foi feita a opção "por abrir o Programa [do Mestrado] ao pensamento mais crítico sobre a escola, que chegava de fora, e passou-se a pesquisar a própria ideologia da Reforma Educacional", trazendo o pensamento social e histórico para a educação. Segundo Arroyo, numa tentativa de ir além de "aplicar ciências sociais à educação", este Programa 
se abriu a candidatos graduados em qualquer área que trouxessem uma "prática educativa menos acadêmica" para uma problematização e conferissem uma compreensão "político-educativa" às pesquisas (ARROYO, 1982, p. 111).

Entende-se, então, que as mudanças propostas e desenvolvidas pelo Programa de Pós-Graduação da FaE-UFMG proporcionaram a acolhida de pesquisadores/professores da RME-BH, favorecendo a aceitação de projetos que investigavam temas relativos à reorganização da educação que se processava nas práticas. A apresentação de um Memorial pelo/as candidatos/as, como documento exigido para o ingresso do pósgraduando, trouxe as questões da prática escolar para o âmbito acadêmico e os temas do novo período que a ela se relacionavam, acolhendo as diferenças da realidade escolar.

Nessa perspectiva, a pequena produção dos anos 1980 se abre para as questões importantes da educação nesse período e aponta para as transformações que virão nos anos seguintes.

\section{ANOS 1990: cresce a produção e surgem novos temas}

Nos anos 1990, o número de trabalhos acadêmicos que têm as escolas municipais de Belo Horizonte como referência aumentou consideravelmente (44 dissertações e duas teses). Esses trabalhos mantinham a perspectiva de denúncia da situação de fracasso escolar, mas apontavam múltiplas experiências e análises sobre elas.

Constatava-se a existência de pesquisas com relatos de experiências consideradas inovadoras e diferenciadas, relacionadas ao ensino na sala de aula, envolvendo diferentes campos do conhecimento: linguagem, educação física, história, matemática, ciências, línguas estrangeiras. Muitas experiências iniciadas na década anterior eram agora descritas e analisadas. São propostas de planejamento, de desenvolvimento e de análise de ações diante de dificuldades nas práticas escolares, tanto no campo da gestão compartilhada quanto no que diz respeito à melhoria dos níveis de aprendizagem dos estudantes, principalmente daqueles que eram considerados fracassados.

Esse período, relacionado à situação de crise e fracasso no ensino fundamental denunciada desde a década anterior, trouxe também à tona a questão do currículo. Esse tema aparece explicitamente em alguns 
trabalhos. Nesse âmbito, surgem estudos que tratam de temas como o papel das disciplinas no currículo, o espaço a elas destinado, a representação da comunidade escolar sobre elas, a valorização e o prestígio desses conhecimentos organizados.

Outros trabalhos, também relacionados à presença das classes populares na escola, analisam a democracia na gestão escolar e a organização do trabalho docente. Assim, são feitas análises dos movimentos que as escolas realizam no sentido da democratização, que levam em conta o enfrentamento de conflitos na gestão e na administração e que consideram a mudança na perspectiva de uma escola em processo de universalização. Tudo isso mostra uma preocupação dos pesquisadores em estudar a escola, em compreendê-la a partir de sua realidade, e não apenas a partir de prescrições curriculares ou administrativas.

O que salta aos olhos, na leitura dos trabalhos, é a complexificação dos enfoques a partir desse período. Estudos passam a contemplar a relação das crianças de classes populares com o conhecimento escolar, abordando aspectos de ordem cultural, social e política e buscando compreender como essas crianças aprendem ou não aprendem, situando múltiplos elementos presentes nas relações cotidianas. Destacam os processos de aquisição e uso da língua escrita e de alfabetização, que constituem um desafio para educandos e educadores. Outros campos teóricometodológicos são buscados para a compreensão dos processos de aqui-sição da leitura e escrita (a lingüística, a linguagem como discurso, os usos e funções sociais da língua, entre outros) e para a ampliação e a reelaboração do conceito de letramento, que estará presente nos trabalhos a partir daí.

A abordagem do "fracasso escolar" também se amplia com a incorporação de análises dos aspectos que caracterizam a cultura dos alunos, sobretudo dos jovens. Esses trabalhos pretendem levar em conta fatores sociais e culturais que influenciam o processo de escolarização, tais como a forma de ser, agir, falar e pensar dos estudantes das camadas populares. Relatos de experiências e de propostas no sentido da inclusão e da aprendizagem continuam a ser realizados com o objetivo de mostrar que esses educandos também podem aprender na escola, a partir de uma estrutura que seja inclusiva, cooperativa e que propicie convivência e diálogo entre culturas. Os trabalhos anunciam a beterogeneidade na composição dos discentes, agora muito mais presente nas escolas, e, muitas vezes, apontam as incertezas que envolvem a prática e a relação professor/aluno. A perspectiva da diversidade cultural passa a ser mais destacada e também as ações específicas da escola diante dela. 
Há forte influência nos trabalhos da tendência pedagógica que coloca o aluno no centro dos processos escolares, movimento assumido por um conjunto de educadores e que se reflete nas novas legislações e projetos pedagógicos. As propostas e práticas educacionais ditas "alternativas" se voltam para o aluno: como ele chega à escola? Como garantir sua aprendizagem, considerando as diferenças e partindo dos conhecimentos que tem? Como garantir para esse aluno um percurso escolar completo? Quem é o educando? Como o professor o vê? Não basta vêlos como alunos, é preciso vê-los "como gente", como sujeitos sociais, na sua totalidade, parte de trajetórias humanas diferenciadas e diversificadas.

Os estudos que abordam os alunos trazem uma riqueza de informação sobre suas características e sobre os conhecimentos prévios que eles trazem à escola. Com isso, questiona-se o conhecimento escolar transmitido de forma única, fragmentada e numa perspectiva de memorização, típico da escola dos anos 1970. Revelam o aluno como sujeito sociocultural, como um sujeito de direito ao conhecimento como parte de sua formação social.

Alguns trabalhos abordam a avaliação na perspectiva das mudanças da escola, considerando necessário equacionar os altos índices de reprovação tão marcantes no período e com a preocupação de buscar alternativas inclusivas. São estudos que visam a compreender concepções, sentidos e significados atribuídos à avaliação escolar.

Também foram elaboradas dissertações sobre o trabalho docente, em análises globais e em análises de "práticas" diferenciadas, centradas na mudança do trabalho do professor na escola. Situam experiências de uma organização do trabalho docente diferente daquela anterior à ampliação da participação docente na gestão e na administração da escola.

Os trabalhos acadêmicos dos anos 1990 também ampliam a abordagem da docencia, destacando o papel do/a professor/a nesse contexto, situando suas posturas, representações, aprendizagens, trajetórias, conhecimentos e saberes, mudanças e resistência às mudanças, formação e identidade. Os pesquisadores mostram que os docentes se preocupam com a própria prática pedagógica, conversando, expondo, refletindo e expressando pesquisas também sobre a prática.

Nesse sentido, alguns trabalhos ampliam as análises sobre as complexidades da prática pedagógica. Aparecem mais delineadas as categorias cotidiano e representação social como referenciais de análises, além do estudo mais sistemático da estrutura escolar na sua relação com a produção do fracasso escolar. 
A questão de fundo que permeia esses estudos, em continuidade com o que se inicia nos anos 1980, é a percepção da mudança educativa gerada no interior da escola, e não apenas a partir das políticas públicas prescritas. Dirigem-se ao cotidiano, às práticas, à sala de aula, à relação professor/estudante, professor/estudante/conhecimento, práticas culturais na escola, entre outras categorias. Ao longo dessa década, alguns estudos abordavam os saberes produzidos nas práticas pelos docentes e suas relações com os saberes da formação inicial e continuada.

A ampliação da organização de professores, especialistas e estudantes em associações e sindicatos, a ampliação do número de professores pesquisadores da própria rede municipal e a multiplicidade de eventos para o debate da educação até os anos 1990 revelam um alargamento da consciência política e profissional docente. Esse processo talvez tenha influenciado os estudos sobre o trabalho docente, principalmente sobre suas condições objetivas, tais como, a parcelarização, a fragmentação e a hierarquização.

Como reflexo do restabelecimento de relações mais democráticas no país, iniciadas na década anterior, pode-se perceber também um avanço da democratização nas relações de poder no interior da escola, que se manifesta na construção de projetos coletivos. Esse fenômeno é analisado pelas pesquisas que enfocam algumas práticas de cooperação $e$ colaboração como alternativas às dificuldades do trabalho ainda fragmentado. É importante notar que algumas dessas iniciativas foram protagonizadas pelos próprios pesquisadores, que se propuseram investigar projetos desenvolvidos e/ou situações vivenciadas por eles mesmos, por meio de relatos analíticos das possibilidades de transformação de suas próprias práticas escolares.

Os temas infância, creches e a pré-escola aparecem ainda nessa fase, de modo bem incipiente. Estudam a identidade profissional e a escolarização de educadores de creche comunitária e constroem novas percepções no sentido do desenvolvimento profissional para a tarefa de educar nessa idade.

Nos anos 1990, surgem trabalhos sobre as identidades de gênero e de raça/etnia que aprofundam as discussões sobre o preconceito, a discriminação e os processos de inclusão de minorias. Ao abarcar a perspectiva da universalização e da inclusão, esses temas se destacam e constituem estudos inéditos na história educacional brasileira. Também surgem trabalhos que enfocam identidades geracionais, investigando aspectos relativos a diferentes etapas da formação e do desenvolvimento humano, em especial à infância e à adolescência. 
Ao final dessa década, surge o primeiro trabalho que aborda a questão da inclusão escolar de pessoas com deficiência. Trata-se de um estudo sobre a construção do sentido de aprendizagem para o estudante portador de surdez.

Aparece, também, o primeiro trabalho que aborda a educação de jovens e adultos - EJA - como modalidade de educação, analisando uma experiência de formação profissional no ensino fundamental para educadoras de creche. Há uma análise de documentos e ordenamentos do sistema de ensino do município de Belo Horizonte entre 1990 e 2000, revelando a política implementada e a formulação teórica direcionada para esse público.

Em pesquisas mais abrangentes, situam-se, também nesse período, estudos sobre as novas funções sociais da escola e suas interações com a comunidade, a reorganização escolar e a dinamização da gestão, com a construção de projetos político-pedagógicos. Trata-se da única pesquisa com abordagem quantitativa/qualitativa. Apresenta um levantamento do perfil dos profissionais do magistério, desde os anos iniciais do ensino fundamental, destacando aspectos pessoais e culturais, trajetórias e condições de trabalho, compondo, assim, uma "fotografia" das professoras das escolas municipais naquele período.

Outros trabalhos enfocam a comunidade escolar e a relação com a família. Há um estudo específico sobre as línguas estrangeiras que analisa práticas de "centros de línguas" existentes na RME-BH naquele período, apontando a necessidade de valorizar a inclusão de línguas estrangeiras na vida regular da escola pública.

Entre as metodologias de pesquisa utilizadas nos trabalhos dos anos 1990, predominam a perspectiva etnográfica e o estudo de caso, seguidos pela pesquisa colaborativa, narrativas e trajetórias de vida, mediante a utilização de diferentes procedimentos, tais como a observação sistemática do cotidiano escolar, a entrevista, o questionário e as filmagens.

A análise presente nos estudos desse período considera, inicialmente, o plano das políticas nacionais, já parcialmente situado, quando o país vive uma crescente participação social e a sociedade organizada discute as políticas públicas. Essa abordagem é ampliada com as idéias de globalização e neoliberalismo que estão em debate, influenciando a educação duas grandes linhas de ação: uma articulada às proposições coordenadas por financiamentos do Banco Mundial e de países alinhados aos EUA, onde a perspectiva da privatização é preponderante e se instituem sistemas avaliativos reguladores e, pode-se dizer, 
uma perspectiva técnica e aligeirada de formação na educação básica e superior. Essa linha tentou ser dominante a partir de orientações do governo federal, durante toda a década, tendo o apoio de grupos privatistas. Contudo, paralelamente, outra perspectiva também se mobilizava, sob os ideários dos movimentos de educadores em defesa da escola como um tempo/espaço de formação para a cidadania, para a diferença e a inclusão social. As bandeiras por uma "escola para todos", por participação e democracia escolar, estavam fortemente colocadas pelos grupos organizados, especialmente de docentes. Pode-se observar que esse debate e as teorias que o alimentam se apresentam como referência em muitos trabalhos analisados.

Ainda nessa década, como desdobramentos da Constituição Federal promulgada em 1988, foi aprovada a Lei de Diretrizes e Bases da Educação Nacional (LDBEN/9394) de 1996. Essa lei assume o princípio da diversidade e da pluralidade, amplia a flexibilização e as possibilidades de organização dos sistemas escolares, mas estabelece um sistema nacional de avaliação como medida reguladora. As palavras de Cury (2005, p. 35) explicitam as forças presentes no texto final da lei:

Fica clara a opção da Constituição Federal de 1988 e, à sua luz, a da nova LDB e de outras leis infraconstitucionais em considerarem a diferença constituinte do princípio da pluralidade. A inserção da diferença na Constituição e nas outras leis não se deveu a uma luz especial de uma comissão de sábios, ou a uma doação magnânima de elites compadecidas, ou de déspotas esclarecidos. A conjugação complementar, recíproca e dialeticamente relacionada da diferença com o princípio da unidade essencial da igualdade entre todos os homens decorreu de pressões conscientes feitas por grupos sociais que, de longa data, foram objeto de violência seja ela econômica, política ou cultural, seja ela física ou simbólica.

Como parte dessa política são publicados os Parâmetros Curriculares Nacionais - PCN's -, em 1998/2000, documentos que buscam implantar referências curriculares comuns e oferecer indicadores de avaliação, que vão ganhando, gradativamente, espaço nas ações geral e local.

Amplia-se a preocupação da sociedade organizada com os direitos dos cidadãos, em contundente denúncia das discriminações de raça/etnia e gênero, com a inclusão de pessoas deficientes e, já no final da década, com a disseminação de propostas e iniciativas de "ações afirmativas". Também os direitos incidem sobre os agrupamentos sociais com base em suas idades, ganhando destaque a infância, a juventude e o jovem-adulto, com suas características e marcas da cultura de seu grupo de formação. 
A tudo isso incorpora-se a tecnologização da sociedade, com a ampliação do uso da web e as políticas públicas que ampliam a oferta de computadores para uso de setores sociais que não tinham acesso anteriormente.

As dissertações e teses que tratam da "infância", "juventude" e "tecnologias" aparecem justamente nessa década, quando esses temas estão presentes nas reivindicações e nas pautas diversas e, também, nas políticas públicas do período.

Os anos 1990 caracterizam-se por inúmeros acontecimentos relevantes, como um desaguamento de ações dos movimentos sociais e, no interior deles, do "movimento de renovação pedagógica". O governo municipal de Belo Horizonte dos anos iniciais dessa década passa a reconhecer os projetos político-pedagógicos das escolas, que, apesar de múltiplos e ricos, mostravam-se fragmentados, com ações realizadas de modo isolado. Esse reconhecimento desencadeia a formulação de um projeto global para o município.

Em 1993, com a mudança no governo municipal de Belo Horizonte, iniciou-se um processo, concluído em 1995, que resultou na implantação do Programa Escola Plural'. Tratava-se de um programa que foi e continua sendo muito debatido no município. Nenhum trabalho acadêmico sobre a RME-BH pôde, a partir desse momento, desconsiderar o Programa Escola Plural, seja como referência para análise de diferentes questões da educação, seja pelas características da proposta. Também no âmbito da gestão municipal, nesse período desenvolveu-se a política de consolidação do sistema municipal de ensino e foi criado o Conselho Municipal de Educação - 1998.

Finalmente, para a análise das questões relativas a esse período, é importante considerar/destacar a pós-graduação da FaE-UFMG. Nesse programa, até a segunda metade da década de 1990, prossegue a perspectiva anteriormente descrita, ou seja, a abertura para pesquisas sobre a experiência e as questões que surgem dos movimentos sociais, construindo, a partir desses resultados, novas teorizações para a educação.

A partir de 1997, o programa sofre mudanças, por exigência da CAPES/MEC. Inicia-se, então, a constituição de linhas de pesquisas por agrupamento dos pesquisadores e uma reforma curricular que se contrapõe à flexibilização do modelo até então vigente. Ademais, o número de vagas oferecidas pelo Programa para o mestrado e o doutorado tem um crescimento superior a 100\% entre os anos 1990 e 2000 . Segundo documentos do Programa, as questões da emergência dos sujeitos e da diversidade social na educação ganham espaço importante na pesquisa, coincidindo com as configurações dos trabalhos relativos à RME-BH nesse período. 
ANOS 2000:

\section{grande ampliação e maior diversificação da produção}

A partir dos anos 2000, o número de trabalhos cresce bastante e se diversifica ainda mais. Muitos temas anteriormente abordados continuam a ser pesquisados e novas questões surgem nas dissertações e teses sobre/na RME-BH (106 dissertações e oito teses).

Como na década anterior, muitos são os trabalhos envolvendo leitura e escrita, literatura, convivência com formas diferenciadas de linguagens, entre outros aspectos. O tema letramento aparece em análises mais abrangentes, em que se destacam as diversas dimensões da prática da leitura e da escrita em sala de aula, as relações e interações entre elas, a dimensão política da aquisição da língua e a alfabetização de jovens e adultos. As análises apontam para mudanças nos processos de alfabetização nas escolas, adotando a perspectiva dos estudos da psicogênese da alfabetização. Destacam-se também a discussão do conceito de alfabetização, seus avanços e limitações nas práticas do/as professore/as, as dificuldades e os impasses vividos diante dos novos processos da alfabetização, principalmente diante da diversificação dos estudantes. São também realizados estudos sobre a leitura literária, a relação de sujeitosleitores com os livros, especificamente os jovens, o uso do livro didático na metodologia de projetos e nas interações na sala de aula.

Os estudos sobre questões relacionadas à educação de jovens $e$ adultos apresentam considerável ampliação, no que tange às políticas públicas para essa modalidade de formação, à formação política dos professores de EJA e, também, aos aspectos relacionados diretamente à aprendizagem dos estudantes, suas características e especificidades. Pesquisas aprofundam temas relativos ao currículo, à avaliação, à organização dos tempos e espaços escolares para o jovem e o adulto trabalhador na escola. São também analisados programas específicos de EJA.

As pesquisas sobre EJA refletem uma mudança de concepção na educação de jovens e adultos, tratando-a como uma nova modalidade de ensino, uma etapa de formação que ultrapassa os modelos compensatórios. Assim, o educando deixa de ser um indivíduo pobre e carente e passa a ser visto como sujeito, com uma identidade, com características próprias e procura-se compreender suas necessidades e projetos. Seus conhecimentos são valorizados e dedica-se especial atenção às relações entre educação e trabalho.

As pesquisas também mostram preocupações dos docentes com a evasão nos programas de EJA. Destacam que as relações desses edu- 
candos com a escola expressam dificuldades, por se tratar de um espaço de difícil combinação com sua rotina de trabalhador, mas também prazer, por tratar-se de um espaço privilegiado de vivência, convivência e conquistas. Constatam que a maioria dos alunos acredita que a escolarização lhes dará maior independência e mais chances no mercado de trabalho. No entanto, as investigações analisadas revelam que os currículos da EJA continuam discrepantes em relação à vida social dos estudantes, apesar dos esforços de articulá-los. Entre as dificuldades de aprendizagem apontadas, permanecem aquelas relacionadas ao letramento. É mencionado o problema da grande rotatividade dos professores da EJA e também a percepção de certo isolamento dessas experiências nas escolas municipais. Contudo, os estudos também relatam práticas e experiências inovadoras, em resposta aos desafios dessa modalidade de ensino, destacando os aspectos positivos dos projetos analisados.

Nessa década, as análises sobre o Programa Escola Plural aparecem em maior número e pode-se mesmo afirmar a inexistência de trabalhos referenciados nas escolas municipais que não considerem esse programa. Assim, os estudos se referem à reforma e à mudança, à avaliação, à relação escola/família/comunidade, à formação de professores, ao currículo, à gestão escolar, à organização do trabalho docente, à aprendizagem e à não-aprendizagem, à organização dos tempos e espaços escolares. Engajamento e resistência no âmbito da RME são também analisados diante do novo programa político-pedagógico. O trabalho docente retorna como tema das pesquisas que, nesse momento, enfatizam as tensões que caracterizam os processos de constituição do coletivo, a rearticulação dos tempos e a organização dos ciclos nas escolas, durante os primeiros anos de implementação da Escola Plural.

Os numerosos estudos sobre a Escola Plural, considerando-se os anos finais da década de 1990 e os cinco primeiros anos da década 2000, vão indicar controvérsias, ora apontando avanços nas práticas e nas elaborações de propostas e projetos para a universalização da educação escolar, ora apontando limitações e dificuldades, discordâncias, resistências e polêmicas. Refletem, assim, as controvérsias dos processos de transformação da escola.

As mudanças de políticas públicas, em nível nacional e municipal, parecem influenciar o crescimento das pesquisas que abordam o direito à educação escolar pública, as novas formas de gestão que valorizam a participação da comunidade e as políticas assistenciais. Surgem estudos sobre programas mais específicos, como o bolsa-escola e o 
cadastro escolar, além das estratégias de abertura de vagas e da gestão político-pedagógica no âmbito da escola e da RME-BH, sob a ótica do direito à educação. Alguns estudos ainda enfocam a atuação do/a diretor/a na gestão político-pedagógica da escola e o Conselho Municipal de Educação, na perspectiva da gestão democrática da educação no município.

Pode-se afirmar que, desde o início dos anos 1990, desdobram-se conseqüências na educação municipal como fruto de elaboração e intervenção governamental, na forma de propostas, projetos, diagnósticos, avaliações, etc. De outro lado, mas nem sempre de modo oposto, grupos de docentes se organizam, discutem as políticas, criticam e também fazem propostas. Ao analisar os trabalhos relacionados às políticas públicas e à gestão, foi possível observar que o entendimento de "políticas públicas" se relaciona com ações do poder municipal e, no mesmo sentido, à participação de outros agentes organizados do sistema educacional e da comunidade social. Essa participação é considerada "emancipatória". É analisada também a existência de um descompasso entre as ações de sentido inovador e transformador e as concepções e representações de grupos e sujeitos da educação que delas participaram. Nesse sentido, a participação é amplamente defendida nas análises como uma forma democrática e, também, como "elemento de regulação democrática", capaz de produzir formas variadas de controle e de responsabilização.

Outros temas sobressaem nos estudos sobre a gestão: a análise do programa bolsa-escola, considerado "marginal" diante das demandas das camadas populares, mostra benefícios inegáveis no sentido de redução do nível de carências materiais das famílias e do trabalho infantil e do fortalecimento do espaço da família para crianças e adolescentes. Sobressaem, também: a metodologia de desenvolvimento do programa de reconhecimento e aproximação entre o Estado e o cidadão; a análise do "cadastro escolar" que implementa uma proposta democrática de acesso da população à escola pública, contribuindo para explicitar os dados de inclusão e carências, diante do movimento de universalização da escola; e o estudo do Conselho Municipal de Educação, cujas dinâmicas políticas ultrapassam o setor educacional, fazendo com que eles sejam instrumentos privilegiados do processo de democratização social e da gestão educacional.

As investigações sobre o trabalho docente situam a docência no cotidiano escolar, considerando o desenvolvimento individual e coletivo, principalmente a partir do movimento de universalização da educação. Pode-se perceber pontos convergentes nos trabalhos, desde os anos 1990, nos quais se destacam o movimento de tomada de decisão coletiva em 
todos os níveis e, em alguns trabalhos, análises que indicam a "pouca eficácia" desses mecanismos e, também, a dificuldade de funcionamento dos espaços mais coletivos de discussão e ação. Tudo isso se reflete na vida do professor, de modo particular na precarização da saúde, que se revela como um tema importante nos estudos analisados. Ao final, com a ampliação das funções na escola, constata-se uma intensificação do trabalho docente e, de modo mais amplo, o adoecimento dos professores.

A intensificação do trabalho docente se verifica na sala de aula e na escola como um todo. Ampliam-se as preocupações do corpo docente diante da diversidade de questões de ordem social mais presentes na escola. Destaca-se, também, a dupla jornada da mulher. O estudo dessa temática deixa a indicação de que a proposição e a implementação de projetos de reforma educacional não podem negligenciar as condições reais de trabalho dos docentes. Contudo, mesmo diante desse quadro complexo, em que se destaca o "adoecimento dos docentes", são encontrados estudos em que a docência desperta satisfação e realização.

No final da década anterior, foi realizado o primeiro trabalho que tratava, de forma tangencial, a questão de gênero, mas foi no início dos anos 2000 que se observou o crescimento das pesquisas que tratavam a diversidade identitária de professores e estudantes da RME-BH. As especificidades de gênero, raça, opção religiosa, opção sexual e conformação geracional, além das questões relativas à inclusão da pessoa com deficiência, estavam mais presentes nas pesquisas.

Os trabalhos que abordavam questões de raça e etnia mostravam educadoras que passaram por situações de preconceito e denunciam o racismo em nossa sociedade em suas diversas formas. Apontam também que os currículos escolares têm acolhido esse tema, possibilitando reflexões e práticas na escola que mostram uma visão estereotipada da pessoa negra.

Os estudos sobre a inclusão de estudantes com deficiência e/ou necessidades especiais na escola confirmavam a presença da política pública no cotidiano escolar e ampliavam conhecimentos sobre o assunto. Revelavam, contudo, que os educadores se diziam desinformados, apresentavam dúvidas e dificuldades na implantação das propostas de inclusão e também questionavam a ausência do tema em sua formação.

Os estudos sobre gênero e sexualidade eram iniciais e apresentavam um discurso escolar que buscava a homogeneização, ou seja, o igual, o normal, o bom. Assim, mostravam que o reconhecimento, a identificação e o tratamento do diferente ainda ocorriam como estratégia de adaptação ao sistema. Tratava-se, portanto, de um tema candente. 
Um estudo sobre a identidade de professores homens nos anos iniciais da escolarização mostrava que os homens se consideravam capazes de desenvolver uma prática nesse período da formação básica e que o comportamento masculino influenciava positivamente a educação da criança. Ao contrário das mulheres, representadas por eles como muito sentimentais, os professores se auto-representavam como mais objetivos e racionais.

As relações entre os grupos familiares e a escola eram destacadas em estudos nessa fase, sempre margeadas pelas diferenças de origem social, cultural e econômica. Reconheciam que não há uma tradição de pesquisas sobre esse tema e, ainda, a ausência de pesquisas sobre o impacto da intervenção de agentes públicos na esfera domiciliar, bem como a sua repercussão no processo de socialização e escolarização dos educandos.

Questões relativas à indisciplina, à participação coletiva nos processos avaliativos e formativos, assim como os grupos estudantis nas relações escolares, estão presentes em alguns trabalhos. As visões da infância, da adolescência e da juventude marcaram as práticas escolares nas relações cotidianas docentes/discentes, na educação infantil, no ensino fundamental e no médio.

Sobre cultura e educação infantil, pode-se considerar, ao final, ainda tímida a produção. Os trabalhos elucidam o universo cultural da infância, por meio de suas vozes, dentro e fora do espaço escolar. Segundo as análises feitas, os trabalhos teoricamente se contrapunham à perspectiva desenvolvimentista que predominava nos estudos sobre a criança, apontavam a complexidade da produção do conhecimento na infância e indicavam que a educação infantil requer profissionais "competentes e sensíveis", demandando uma formação mais adequada; revelavam a carência de estudos voltados para as crianças de 0 a 3 anos; analisavam o movimento de luta pró-creche, a política de convênios desenvolvida no município que tem sua raiz na perspectiva da assistência social; revelavam a lentidão das definições e da implementação de iniciativas do governo diante das demandas. Era apontada uma contradição segundo a qual políticas que ampliam e valorizam a educação infantil não repercutem na mesma medida na valorização do profissional docente que para ela se volta.

A temática juventude se mostrava ainda mais visível na sociedade a partir dos anos 1990, como já citado. O aparecimento desse tema pode estar relacionado à emergência dos estudos sobre os sujeitos da educação e, também, sobre políticas públicas mais contundentes. As pesquisas mostravam, inicialmente, uma juventude "problema", enfatizando a 
violência e a criminalidade. Foi, no entanto, a partir da ampliação das ações públicas voltadas para a juventude nesse período que grande parte dos trabalhos enfocavam essas questões. O jovem aparecia nas análises como sujeito social e cultural, seus conhecimentos, concepções e comportamentos eram mais valorizados, ampliando-se também a compreensão de seu "lugar" na escola. Tratava-se de um tema emergente.

As investigações sobre o currículo escolar avançavam ainda mais e refletiam as experiências e tentativas de mudanças dos conhecimentos escolares, passando a focalizar temas de interesse social, temas transversais e interdisciplinares, tais como a educação ambiental, a sexualidade, a corporeidade, a cidadania, entre outros. A pedagogia de projetos também aparecia mais na pesquisa como uma prática que possibilitava a articulação de conhecimento, que favorecia o trabalho cooperativo no espaço/tempo escolar, perspectiva esta presente no Programa Escola Plural. Os trabalhos desenvolvidos abordavam práticas escolares, saberes docentes e projetos diversos envolvendo o ensino da Matemática, da Física, da Química, das Ciências, da Geografia, da Educação Física, das Artes, da Língua Portuguesa, das Línguas Estrangeiras e da História.

Seguindo os estudos relativos à Língua Portuguesa (alfabetização, letramento, literatura, etc.), estavam presentes, em maior número, as dissertações e teses no âmbito da educação matemática e da educação física. No campo da educação matemática, estudos sobre a aprendizagem e sobre a prática docente discutiam o papel da Matemática nos processos de "fracasso escolar". Indicavam uma busca de compreensão do ensino da disciplina na formação de crianças e jovens, ampliando e diversificando metodologias, ao mesmo tempo em que analisavam práticas nas quais as relações professor/aluno eram mais horizontais e positivas. No campo da educação física, destacavam-se os estudos que visavam à compreensão do movimento e da pluralidade de significados das práticas corporais, consideradas como parte da cultura humana a ser trabalhada e reinventada nas escolas.

Ainda nesse período, a avaliação escolar do aluno tinha enfoque em alguns trabalhos. Ganhavam visibilidade as questões da promoção ou retenção de estudantes, ano a ano, e a forma como esses resultados repercutiam na perspectiva da universalização e da inclusão. A avaliação institucional também era pesquisada por meio da análise de programas pedagógicos em desenvolvimento. Os temas focados na avaliação, de modo geral, relacionavam-se com questões suscitadas pela implantação da Escola Plural.

A questão da formação docente é relevante e congregava muitos trabalhos. O paradigma do professor reflexivo era uma forte referência 
teórica, relacionando-se com os processos de formação em serviço. As pesquisas se referiam à prática reflexiva e à formação, na qual os professores eram vistos como sujeitos socioculturais produtores de saberes que advinham de suas práticas. Predominavam as investigações sobre a formação continuada que mostravam um acúmulo de experiências de formação nessa modalidade, mas indicavam descontinuidades entre elas e o desenvolvimento profissional. Outros temas estavam presentes nesses estudos: encontros entre docentes, relatos e trocas de experiências valorizadas como processos formativos, trajetórias de educadores que atuaram no CAPE e a discussão do próprio centro de formação, sua política, suas controvérsias e possibilidades.

A condição docente, entendida sob múltiplas dimensões relacionadas à vida pessoal e profissional, é focada nos trabalhos sobre o/a professor/a de modo mais amplo. Nela os docentes são investigados em suas diversas dimensões: corporal, afetiva, profissional, histórica, condição de gênero, raça/etnia, entre outras.

$\mathrm{Na}$ organizaçãa do trabalho docente, mais uma vez, destacavam-se, como referência, os estudos que abordavam questões relativas à saúde do trabalhador em educação e à sua participação sindical.

Há ainda que se destacar vários estudos sobre a incorporação das tecnologias informacionais nos processos educativos. Os estudos das tecnologias na educação realizados na RME-BH retratam as mesmas questões que situam a temática na educação em geral, no momento histórico em que um elemento tão importante é introduzido nas práticas. São pesquisas sobre o uso da informática na formação docente, em processos de ensinoaprendizagem dos estudantes, nas práticas de inclusão e na gestão pública escolar. Os trabalhos explicitam o processo contraditório que envolve tecnologia e educação, quando leva a um controle e à intensificação do trabalho docente, ao mesmo tempo em que ampliam as condições para a criatividade e a autonomia. A tecnologia marca presença na formação na educação básica e no trabalho docente, mas a pesquisa desse tema é ainda incipiente e merece mais atenção em futuras investigações.

A prática pedagógica é um tema que se amplia como objeto de reflexão nas pesquisas, tanto em análises de escolas, como de salas de aula e do cotidiano escolar em geral. Esses estudos passam a focalizar o ensino de capacidades e habilidades disciplinares e interdisciplinares e de suas relações com os processos de socialização na escola. A prática pedagógica, foco que abriga o maior número de trabalhos, abarca análises no sentido da inovação e da resistência, para apontar avanços e/ou dificuldades. 
As análises dos trabalhos sobre a prática pedagógica vêem confirmar o movimento observado na produção como um todo, ou seja, a emergência da prática pedagógica como foco das pesquisas quando há um deslocamento do "olhar" dos próprios professores e pesquisadores do sistema para a escola. De um modo geral, as pesquisas se voltam para o ensino fundamental, abordando diferentes disciplinas, relatando experiências, analisando saberes e aprendizagens. O fazer docente é compreendido a partir de suas limitações e possibilidades no cotidiano escolar, como espaço de existência e atuação, de reconhecimento dos sujeitos nela envolvidos e de sua transformação. Relatos de práticas, suas potencialidades e limitações, reflexões sobre as práticas, complexidade e ambivalência das dinâmicas de interações vividas por professores e estudantes na sala de aula são referências fundamentais desse foco temático.

As metodologias adotadas nos trabalhos são, em sua maioria, denominadas pelos autores como estudos de caso em perspectiva etnográfica, em que se utilizam diferentes instrumentos na pesquisa de campo, como a observação, a observação participante, a entrevista, os questionários, as filmagens e as gravações.

Sobre o contexto de produção dessas pesquisas, pode-se considerar que a conjuntura política nacional reforçava as tendências gerais já verificadas nos anos 1990, no sentido de democratização das instituições, um processo necessariamente complexo em um país com as condições do Brasil, e que não será analisado neste texto.

Mudanças políticas no âmbito federal são efetivadas com o novo governo, no decorrer dessa década, colocando um conjunto de novos temas na ordem do dia, como a dívida externa, a reforma agrária, a distribuição de renda, a saúde e a educação para todos, entre outros. Assim, o país vive uma fase mais ampla de construções, reconstruções e projetos políticos e sociais, na qual se destacam os temas relativos aos direitos básicos e essenciais das camadas mais pobres, aos direitos relativos às idades de formação, valorizando a infância, a juventude, a idade adulta e a velhice. Ganham também relevância o debate e as ações relativas ao direito da mulher, dos negros, das pessoas com deficiência. Múltiplos temas fluem nesse período e são colocados mais claramente na sociedade e também se transformam em objeto de estudo, como os já referidos na pesquisa sobre/na RME-BH.

Nessa direção, Romualdo Portela de Oliveira (2007) explica que, mesmo considerando a existência de uma "agenda mundializada" para a educação, "em cada país sua concretização se dá com diferenças, em 
ênfase e amplitude, decorrentes de história e trajetória específicas" (p. 664). Entende o autor que as reformas educacionais implantadas mais recentemente no país consideram peculiaridades da conformação da sociedade, condições políticas e materiais, movimentos de agrupamentos sociais organizados, projetos de dirigentes governamentais, entre outros fatores, que exercem forte influência no que vai se praticando efetivamente como política, no caso, como política educacional.

O autor salienta também a "importância significativa" da universalização da educação básica, em particular, do ensino fundamental, nas últimas décadas no Brasil. Apresenta dados de fluxos escolares dos anos 1970 a 2000 e observa que os tradicionais mecanismos de exclusão escolar têm sido minimizados. Contudo, analisa que há uma "tensão" entre oferta de vagas (direito ao ensino, ampliação do sistema educativo, superação de "barreiras organizacionais" dentro dos sistemas) e a "qualidade para amplos contingentes da população ou sua negação, o que pode tornar inócua a democratização do acesso, quer seja por sua distribuição diferenciada, quer seja por, e também, relegar a qualidade a nichos de privilégio no interior do sistema educacional” (OLIVEIRA, 2007, p. 666). Desse modo, o autor entende que há positividade no processo de universalização vivido no Brasil, posto que se equacionam - pelo menos parcialmente - problemas históricos vividos com a exclusão. No entanto, não deixa de colocar para a educação novas questões e novos desafios, em especial, situa a baixa qualidade do ensino e outros problemas que ainda permanecem.

Uma análise dos anos 2000 aponta algumas questões de importância para o entendimento do contexto. São elas: uma conduta mais normativa da Secretaria Municipal da Educação, ao longo desses anos, em relação ao Programa Escola Plural; a realização de uma reforma administrativa na estrutura de gestão municipal; a criação de um sistema de avaliação de desempenho para as carreiras salariais no município; a realização da II Conferência Municipal de Educação, em 2002, do II Congresso Político-Pedagógico da RME-Escola Plural, em 2004, e da III Conferência Municipal de Educação, em 2005, na qual foram abordados e debatidos temas relacionados à inclusão social, à gestão democrática, o ao financiamento do ensino, à formação docente, à relação escola/família, à educação infantil e à carreira docente, ao tempo escolar, entre outros.

O tempo escolar tem sido um tema bastante considerado e discutido no "movimento de renovação pedagógica": o tempo do aluno na escola, o tempo do professor nas suas jornadas, o tempo pedagógico da 
organização do trabalho escolar, o tempo das crianças, dos jovens, dos adultos. Também, no âmbito da formação e da aprendizagem, precisam ser considerados os diferentes ritmos e os tempos e espaços que se diversificam. Muitas dissertações e teses desse conjunto consideram a questão do tempo.

Desse modo, constata-se uma grande ampliação e o enriquecimento dos trabalhos nos anos 2000, ainda que tenhamos considerado apenas a sua primeira metade.

\section{ALGUMAS CONCLUSÕES}

Esta pesquisa considerou vinte anos da produção acadêmica sobre/na Rede Municipal de Educação de Belo Horizonte, Minas Gerais. Para realizar uma análise, foi feito o levantamento de informações e a organização dos trabalhos por "focos temáticos", analisados por pesquisadores especialistas. Apresenta-se nesse texto uma análise temporal, procurando situar o "movimento da produção" na sua relação com o contexto mais geral e local, político e educacional.

Há uma multiplicidade de temas/questões/problemas considerados e analisados nos trabalhos acadêmicos sobre/na RME-BH. As elaborações mostram uma grande riqueza. Expressam os conflitos e as controvérsias presentes nas práticas e nos debates no período, em especial em análises que se relacionam com a Escola Plural e os diversos temas que desdobram a perspectiva da "escola para todos". Expressam os rumos da pesquisa na sua dimensão "micro", sem perder de vista o macro.

Toda essa diversidade e diferenciação de temas e problemas constantes dos trabalhos acadêmicos também vem expressar a diversidade e a complexidade dos processos vividos na educação municipal. Não há como generalizar conclusões contundentes, especialmente sobre temas polêmicos tratados nos trabalhos, porque se caracterizam como estudos de casos.

Há um conjunto de relatos e análises de experiências consideradas inovadoras e positivas que valorizam a presença do estudante na escola, considerando seus conhecimentos e possibilidades. Muitos e muitos trabalhos aqui analisados relatam, problematizam e analisam experiências e projetos inovadores que contribuem para o "sucesso escolar".

Como elemento recorrente nas análises dos trabalhos ao longo dos vinte anos, destaca-se o deslocamento do "olhar" do pesquisador para o particular, da referência a definições e orientações da grande política 
pública para a escola, para seus sujeitos, para as pequenas estruturas, para as práticas pedagógicas cotidianas. São valorizadas as ações coletivas, as aprendizagens e saberes da prática, como espaços de formação e aprendizagem de todos da educação. São analisadas experiências de gestão, de ação na comunidade escolar, de novidades e dificuldades impostas à escola pelo processo de universalização da educação. Ganham relevância os estudos dos sujeitos da educação e suas ações, suas características, identidades, diferenças, práticas, saberes, reivindicações, lutas, histórias, memórias, etc. A escola é considerada e analisada como um espaço complexo de formação.

Analisar a escola "como espaço sociocultural" significa, segundo Dayrell (1996), que se tenha em conta o dinamismo do fazer cotidiano por seus sujeitos sociais e históricos, homens e mulheres diferenciados. Segundo as idéias do autor, uma nova vertente busca superar os "determinismos sociais" e a dicotomia "sujeito-objeto" ou "homem-circunstância", surgindo uma análise mais articulada a uma dinâmica de transformação da escola:

(...) O reflexo desse paradigma emergente é um novo humanismo, que coloca a pessoa enquanto autor e sujeito do mundo, no centro do conhecimento, mas tanto a natureza quanto as estruturas estão no centro da pessoa, ou seja, a natureza e a sociedade são antes de tudo humanas”. (p. 137)

A produção aqui analisada mostra, assim, um "movimento" desenvolvido nas últimas décadas, que passa a valorizar a escola como o lugar central do sistema educacional, as ações nela desenvolvidas e os seus sujeitos. Reforça a idéia de que políticas públicas devem ser tratadas com muito cuidado, pois precisam efetivar interlocuções com os diversos sujeitos, considerar as situações de maneira diferenciada e específica, os contextos geral e local.

A realização deste estudo permite ainda dizer que esta é uma rede de escolas que chama a atenção por seu funcionamento peculiar, pelos projetos político-pedagógicos que desenvolve, pelo permanente debate que parece estar instalado na comunidade escolar em torno das questões da educação. A produção analisada reflete isso.

Acredita-se que uma investigação dessa natureza torna-se importante por permitir à comunidade, aos profissionais, aos gestores de políticas públicas e aos pesquisadores o acesso a um conjunto organizado de conhecimentos e saberes.

Considera-se, contudo, ser este um estudo inicial, pois o acervo é muito grande e sabemos que muitas outras análises podem ser feitas. 
Desafios permanecem e diversos temas relativos ao desenvolvimento da educação no período estão em trabalhos em andamento, o que poderá trazer, no futuro próximo, mais luzes para sua compreensão.

\section{ANEXOS}

Quadro I - Relação de dissertações/teses 1986-2005

\begin{tabular}{c|c|c|c|c|c} 
Qüinqüênios & $\mathbf{1 9 8 6}$ a 1990 & $\mathbf{1 9 9 1}$ a 1995 & $\mathbf{1 9 9 6}$ a 2000 & $\mathbf{2 0 0 1}$ a 2005 & Totais \\
\hline Trabalhos & & & & & \\
\hline $\begin{array}{c}\text { Dissertações } \\
\text { Teses }\end{array}$ & 4 & 20 & 38 & 91 & 153 \\
\hline Totais & $\mathbf{4}$ & $\mathbf{2 0}$ & $\mathbf{4 0}$ & $\mathbf{9 8}$ & $\mathbf{1 6 2}$
\end{tabular}

Quadro II - Distribuição das dissertações/teses por qüinqüênios e focos temáticos

\begin{tabular}{c|c|c|c|c|c} 
Qüinqüênios & $\mathbf{1 9 8 6 / 1 9 9 0}$ & $\mathbf{1 9 9 1 / 1 9 9 5}$ & $\mathbf{1 9 9 6 / 2 0 0 0}$ & $\mathbf{2 0 0 1 / 2 0 0 5}$ & Total \\
\hline Focos Temáticos & & & & & \\
\hline Alfabetização e & & & & & \\
Letramento & - & 6 & 5 & 7 & 18 \\
Avaliação & 1 & 1 & 2 & 4 & 8 \\
Cultura e Educação & & & & & \\
Infantil & 1 & 1 & 2 & 2 & 6 \\
Diversidade e inclusão & - & 2 & 4 & 7 & 13 \\
Educação e Tecnologias & - & - & - & 11 & 11 \\
Educação de Jovens e & & & & & \\
Adultos & - & - & 4 & 7 & 11 \\
Formação Docente & - & - & 5 & 14 & 19 \\
Juventude e Escola & - & 1 & 5 & 18 & 14 \\
Políticas Públicas e Gestão & - & - & 3 & 13 & 16 \\
Prática Pedagógica & 1 & 8 & 6 & 23 & 38 \\
Relação família-escola & - & 1 & - & 1 & 2 \\
Trabalho Docente & 1 & 1 & - & 4 & 6 \\
\hline Total & 4 & $\mathbf{2 1}$ & $\mathbf{3 6}$ & $\mathbf{1 0 1}$ & $\mathbf{1 6 2}$
\end{tabular}

$\mathrm{O}$ acervo completo da pesquisa pode ser encontrado em www.fae.ufmg.br/biblio 


\section{NOTAS}

' A pesquisa foi desenvolvida pelo PRODOC, com apoio do Sindicato Municipal dos Professores (SindRede) e da Prefeitura Municipal de Belo Horizonte, Secretaria de Educação, e contou com as seguintes equipes:A pesquisa foi desenvolvida pelas seguintes equipes:

Equipe de organização geral e redação final: Anna Maria Salgueiro Caldeira - PUCMinas, Eustáquia Salvadora de Sousa - PUCMinas (coordenadora), Samira Zaidan - FaEUFMG (coordenadora), Ana Lúcia de Faria Azevedo - RME BH, Claudia Caldeira Soares - RME BH-UNIPAC.

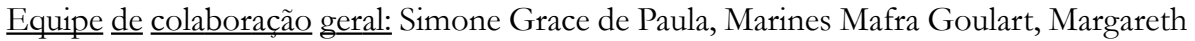
Diniz.

Consultorias: Bernadete Angelina Gatti, Magda Becker Soares, Inês Assunção de Castro Teixeira.

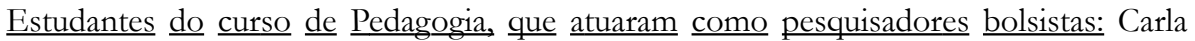
Batista Silva/ Pró-Noturno-FaE-UFMG, Patrícia Haendel de Oliveira Mota - FaEUFMG, Ramon Orlando Filho - FaE-/UEMG.

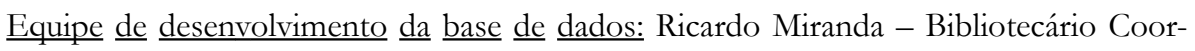
denador, Jacqueline Pawlowski - Bibliotecária Analista de Sistema, Bruno Cezar Resende - Estagiário, Flávia Caroline de Brito Elias - Estagiária, Leandro Miranda Nascimento Estagiário, Thaís Chaves Marinha - Estagiária.

$\underline{\text { Pesquisadores }} \underline{\text { e estudantes que analisaram os trabalhos por focos temáticos: }}$ Alfabetização: Ceris S. Ribas da Silva (FaE-UFMG) e Ingrett da Silva Campos (estudante bolsista). Avaliação: Ângela Imaculada Loureiro de Freitas Dalben (FaE-UFMG), Márcia Ambrósio Rodrigues Rezende (Doutoranda em Educação, professora da RME-BH) e Suzana dos Santos Gomes (Doutoranda em Educação, professora da PUC Minas). Cultura e Educação Infantil: Maria Mafra Goulart (FaE-UFMG), Maria Bernadete Diniz Costa (Mestre em Educação, RME-BH). Diversidade e inclusão: Margareth Diniz (RME-BH), Ramon Orlando Filho (FaE-UEMG). Educação de Jovens e Adultos: Ana Lúcia de Faria Azevedo (RME-BH). Educação e tecnologias: Juliane Correia (FaEUFMG). Formação docente: Júlio Emílio Diniz Pereira (FaE-UFMG), Claudia Caldeira Soares (RME-BH). Luventude e escola: Juarez Dayrell (FaE-UFMG), Simone Grace de Paula (FUMEC). Política e Administração educacional: Mariza Duarte (FaE-UFMG), Adriana Salgado, Ana Carolina Alves, Beatriz Gravelli, Érica Sarubi, Geniana Faria, Jacqueline Moreno Silva, Maria Juliana Silva Jussara, Maria José B. Pinto, Mércia Noronha Pinto, Nilson Silva Júnior, Renata Kelly de Arruda, Thiago Antonio Jorge, Virgínia Matias (Grupo de Estudos GESTRADO). Prática pedagógica: Anna Maria Salgueiro Caldeira (PUCMinas), Eustáquia Salvadora de Sousa (PUCMinas), Maria Eugenia Alves dos Santos (RME-BH), Samira Zaidan (FaE-UFMG), Santuza Amorim da Silva (UEMG). Relação família-escola: Maria Alice Nogueira (FaE-UFMG) e Ramon Corrêa de Abreu (RME-BH). Trabalho docente: Adriana Duarte (FaE-UFMG), Érica Sarubi (GESTRADO/FaE/UFMG, Jacqueline Laranjo (NETE/FaE/UFMG), Jussara Paschoalino (NETE/FaE/UFMG) e Sâmara Araújo (GESTRADO/FaE/UFMG). Maria Helena Augusto (GESTRADO/FaE/UFMG), e Savana Melo (GESTRADO/ FaE/UFMG). Jacqueline Silva (GESTRADO/FaE/UFMG).

2 OLIVEIRA, Leda Barbosa Mendes de. Encontros e desencontros: a entrada no palco escolar. Orientadora: Magda Becker Soares. Dissertação. FaE-UFMG, 1986; PRADO, 
Francisco de Borja López de. O ensino de ciências físicas e a compreensão da realidade. Uma experiência metodológica. Orientador: Oder José dos Santos. Dissertação, FaE UFMG, 1987.

${ }^{3}$ BOURDIEU, Pierre; PASSERON, Jean Claude. A Reprodução, elementos para uma teoria do sistema de ensino. Trad. Reynaldo Bairos de la. E. Francesa, 1970/1975.

${ }^{4}$ Visões que consideram como naturais as dificuldades escolares dos estudantes advindos de camadas populares, graças à "herança biológica" e ao ambiente social.

${ }^{5}$ Alguns desses projetos são apresentados e analisados em dissertações dos anos 1990.

"A Escola Plural propõe a "reorganização dos tempos escolares" para modificar o foco nos conteúdos a serem ensinados para o educando, buscando uma lógica mais inclusiva; propõe destacar múltiplas dimensões formadoras e valoriza a socialização e a convivência; modifica a organização escolar. Ver Cadernos Escola Plural, PBH, SMED, 1995 e 1996.

\section{REFERÊNCIAS}

ANDRÉ, Marli. A pesquisa sobre formação de professores no Brasil - 1990-1998. CANDAU, Vera M. (Org.) Ensinar e aprender: sujeitos, saberes e pesquisa. Rio de Janeiro: CP\&A, 2000.

ARROYO, Miguel G. A Reforma na prática (a experiência pedagógica do mestrado da FAE UFMG). Educação \& Sociedade. Campinas, v.x, n.11, jan., UNICAMP, 1982.

CURY, Carlos R. Jamil. Os fora de série na escola. Campinas, SP: Armazém do Ipê, 2005.

DAYRELL, Juarez. A escola como espaço sócio-cultural. Múltiplos Olhares sobre educação e cultura. Dayrell, J. (Org.). Belo Horizonte: UFMG, 1996.

FREIRE, Paulo. A Educação na Cidade. São Paulo: Cortez, 1995.

FREITAS, Helena Costa L. Formação de professores no Brasil: 10 anos de embate entre projetos de formação. Educação \& Sociedade, Campinas, v. 23, n.80, set., p.137-168, 2002. GATTI, B. A. A construção da pesquisa em Educação no Brasil. Brasília: Plano, 2002.

OLIVEIRA, Romualdo Portela de. Da universalização do ensino fundamental ao desafio da qualidade: uma análise histórica. Educação \& Sociedade, Revista de Ciência da Educação. v. 28, Número especial, Campinas, CEDES, 2007.

PAIVA, Aparecida (Org.). Reflexões sobre a pós-graduação em educaşão no Brasil: a experiência da Fae/UFMG. Belo Horizonte: Autêntica, 1997.

ROCHA, Maria da Consolação. O movimento pela democratização da gestão escolar e as lutas em defesa da escola pública na rede municipal de BH. Revista EM REDE, n.0, SindRede, BH, 2006.

RODRIGUES, Neidson. A educação pós-regime autoritário. FARIA FILHO, Luciano M; PEIXOTO, Ana Maria C. Lições de Minas: 70 anos da Secretaria de Educação. Belo Horizonte: Secretaria de Educação, 2000.

SOARES, Magda Becker. Alfabetização no Brasil: O estado do conhecimento. Brasília: REDUC, 1991.

SOARES, Magda Becker; MACIEL, Francisca. Alfabetização - Brasil. Brasília: MEC Inep/Comped, 2000. 
Recebido: $12 / 09 / 08$

Aprovado: 20/11/08

Contato:

Rua Guilherme de Almeida, 435/101

Santo Antonio

Belo Horizonte - MG

30350-230 